$\begin{gathered}\text { EPiC Series in Built Environment } \\ \text { Volume 2, 2021, Pages 405-413 } \\ \text { ASC 2021. 57th Annual Associated Schools } \\ \text { of Construction International Conference }\end{gathered}$
Built
Environment

\title{
Integration of Dynamic 3-D Models in Construction Management Courses
}

\author{
Sahar Ghanem, Ph.D. \\ Eastern Kentucky University \\ Richmond, KY
}

\begin{abstract}
The traditional lecture method is commonly used to teach Construction Management students. But most of the construction management concepts are hard to convey using this method, and students face obstacles to learning some of the ideas due to the difficulties in visualizing the concepts learned. This research aims to evaluate the influence of using three-dimensional models (3D) as a visualization tool in the construction management undergraduate program. The technique was implemented in three courses at different levels in the curriculum for one semester, and data were collected at the end of the courses. The results showed a strong influence of using 3D modeling in the materials and methods course and construction graphics with less effect in the estimating course. The results encourage expanding the use of 3D modeling and including it in more courses.
\end{abstract}

Key Words: 3D modeling, Construction Management, undergraduate courses

\section{Introduction}

Construction Management (CM) is a hands-on field. Several instructional methods are used to prepare students for their future careers, such as two-dimensional (2D) drawings, field trips, and lab exercises. Students prefer to be engaged in the learning activities and to have an interactive learning environment (Kember \& McNaught, 2007).

These methods are challenging to handle for courses with a large number of students or are too expensive to create and update (Burgett, 2016). The ability to visualize construction plans, specifications, estimation, and scheduling are the key tasks for CM undergraduate students. Good visualization ability is essential to learning these skills (Glick et al., 2012). Although 2D drawings are commonly used as an instructional method for teaching architectural, engineering, and construction (AEC) students, the ability to visualize objects in three-dimensional models (3D) improves students' spatial understanding and creativity (Hain \& Motaref, 2020). It also creates a learning environment that allows students to learn at their own pace (Irizarry et al., 2012). 
Using 3D models in teaching was found to increase students' cognitive learning (Lucas \& Thabet, 2008) and help them to better understand new and complex course materials (Glick et al., 2012). They have been successfully used in Construction Management program classes to improve students' performance in mechanics of materials (Hain \& Motaref, 2020), construction materials and methods class (Schreyer, 2014), National Electrical Code (Burgett, 2016), and estimating (Gier, 2008). The research published by Irizarry et al., 2012 reported an increase of about 10\% in the percentage of correct answers related to concrete construction when 3D models were introduced to students.

Using 3D models will not just help students understand the courses of interest; it will also help them have a strong base for advanced classes and their future careers, as well as support the CM department with limited resources (Gier, 2008).

As students in construction management programs are more likely visual learners (Kolb, 1981), the interaction in 3D models could end the passive learner attitudes found in traditional academic teaching techniques (Sampaio et al., 2010). Creating these models and using them throughout the curriculum could be a starting point for using Virtual Reality (VR), which will further advance the development of educational applications in construction management.

This research aims to evaluate the influence of using three-dimensional models (3D) as a visualization tool in construction management undergraduate courses. The technique was implemented in three courses at different levels in the curriculum for one semester, and students' input was collected at the end of each course.

\section{Methodology}

The concept of 3D modeling was implemented in three classes at different levels in the Construction Management undergraduate program curriculum. The courses used in this study are Materials and Methods of Construction, Construction Graphics, and Estimating. The 3D models are used throughout the semester in both the Materials and Method class and the Estimating class. The model was shared with the students as an interactive 3D model and then discussed with students afterward based on the concept learned. The students are expected to create their 3D house model in graphics class. That will enforce the learning of these skills as students move up in the level of the course.

The evaluation of using 3D models was done by collecting the students' input. The end-of-course evaluation survey was altered to include questions about the students' opinions about this teaching method's effectiveness. The survey was anonymous and not graded, and space for written feedback was also provided. The data was collected at the end of the Fall 2020 semester. The instructor also used the following teaching methods in the classes: lectures, in-class activities, videos, exams, assignments, teamwork, and projects.

\section{Materials and Methods of Construction Course}

Materials and Methods construction course is one of the introductory courses in the program. Usually, it is one of the early experiences the students will have in the construction program. The majority of the class students do not have previous experience in construction nor familiar with the basic terminologies and concepts. The concepts taught in this class require a large-scale lab or continuous 
visits to construction sites. With limited resources, using 3D models will help students visualize the construction systems and assemblies.

Students at this level are not expected to be able to create 3D models themselves. The models are mainly used to visualize the concepts discussed in the class, and they were shared with them to use without them needing to have a background on how to create them.

The traditional class takes place first to discuss the material or method of interest. After grasping the basic terms and knowledge required for the topic, the model is shared with students. Each student can use a cell phone to navigate through the model. Most of the models used can be zoomed, rotated, or exploded to see more details.

The instructor then shows the model on the front screen, and all the information related to it is discussed with the whole class. After students explore the model, the assembly's 2D views are shared with them and compared with the 3D model. That will help students understand the assembly and be able to read the related 2D plans. Figure 1 shows an example of a 2D view, as well as a 3D model for a masonry wall, shared with students in the class.

As this course needs the models only for visualizing, the instructor can use many open resources to cut the time required to build these models from scratch. Among those resources are Sketchup 3D warehouse (Official Google, 2016), where interactive pre-built 3D models are shared. Other materialspecific libraries can also be found, such as the International Masonry Institute (IMI). The Institute created a masonry detailing series, which includes an extensive collection of illustrative construction details and diagrams related to masonry assemblies (IMI, 2019).
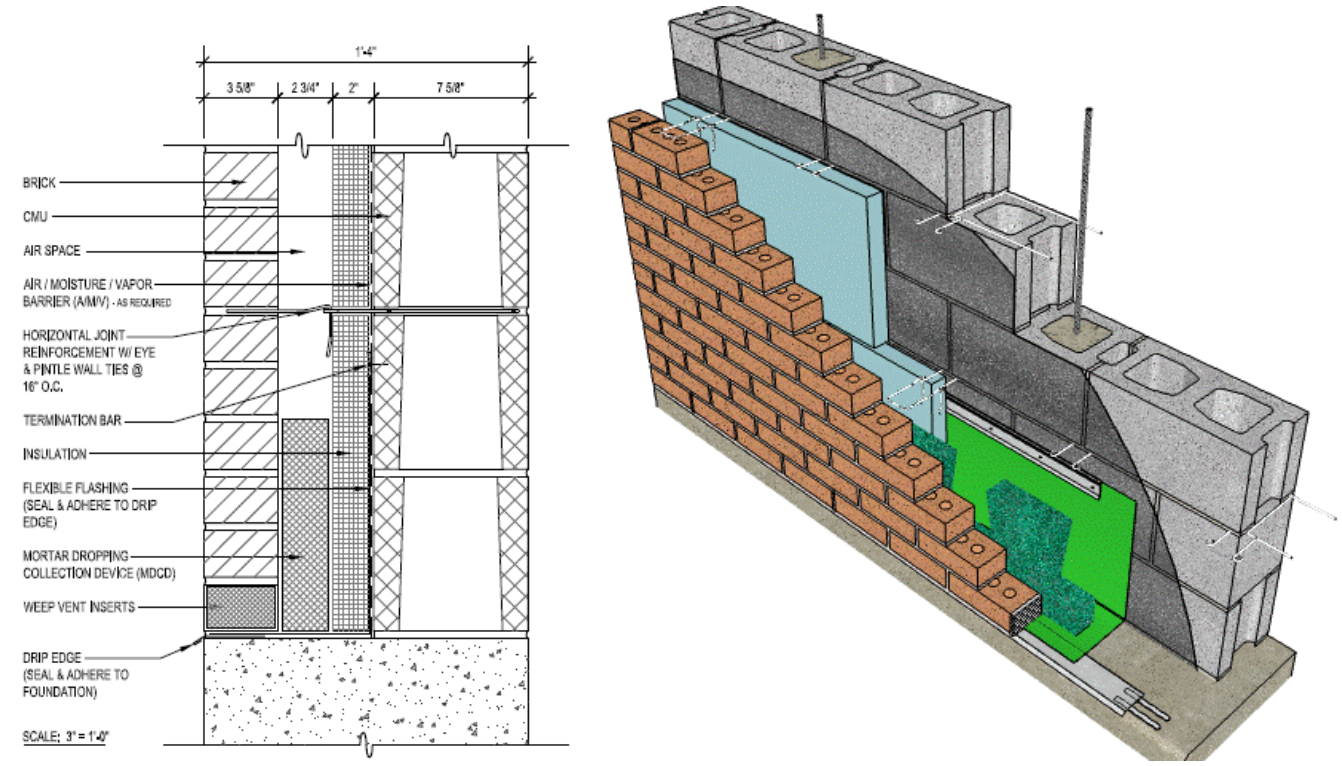

Figure 1. Example of 2D and 3D interactive details of masonry wall (IMI, 2015)

At the end of the semester, 14 students out of 21 registered students answered the course evaluation question related to 3D modeling. The question was, "Do you think using 3D modeling improved your understanding of construction elements?". Seventy-one percent (10 students) of the students agreed to 
this statement, twenty-one ( 3 students) felt neutral about it, and one student disagreed. Figure 2 shows the detailed responses.

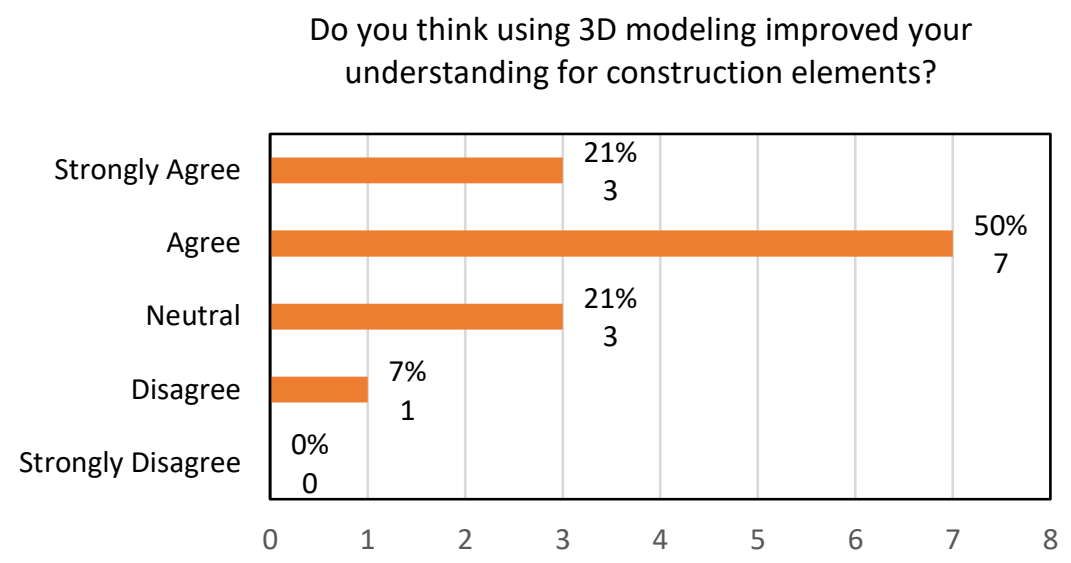

Figure 2. Materials and methods of construction course students' responses

A few students also commented that 3D modeling was one aspect that helped them learn the material. Having access to the models through cell phones was another essential aspect from the students' perspectives.

\section{Construction Graphics Course}

Although the construction graphics course is a 200-level course, students registered in it have a better understanding of the construction industry than students attending the Materials and Methods of Construction course. This course teaches students about different types of plans, views, and sections used in the construction industry. It is also the home of 2D plans drawings. Previously, students used AutoCAD software to draw different views of a residential house.

In an effort to incorporate 3D modeling into the program, the 2D AutoCAD software was replaced by Revit 3D modeling software. The course introduced the concept of BIM in the first few classes and throughout the modeling tutorial. Students had a few difficulties dealing with the software at the beginning of the semester, which was expected. Most engineering software has a learning curve that is slow at the beginning. But once the students grasp the main tools in the software, the learning process becomes more comfortable. By the end of the semester, students were even looking into learning extra concepts not covered by the course.

The course consisted of a few introductory classes to talk about BIM, followed by the basics of construction plans. Afterward, the class was divided weekly to cover the basics of a particular topic, followed by a tutorial on how to perform the work in Revit. Then, more time was given for the students to do the work. In addition to that, written and video tutorials were posted for students to follow. For example, if the week's topic is walls, a short presentation about the different types of walls will be provided. The instructor will show students how to draw walls in Revit, and then they will do the task themselves. 
The more significant benefits came as students were required to edit the assemblies provided in the software. The students have to revise the wall assembly and add the type of materials needed. Choosing the type of materials and the order of these materials in the assembly, helped students see and live in the structure rather than just talking about it.

The course has a semester project available at the beginning of the course. Each student will design a plan for their dream house. After each concept learned in the class, the student will apply the same idea to the project. Based on the 3D visualization, they go back and adjust the design. Figure 3 shows part of a student's final project.
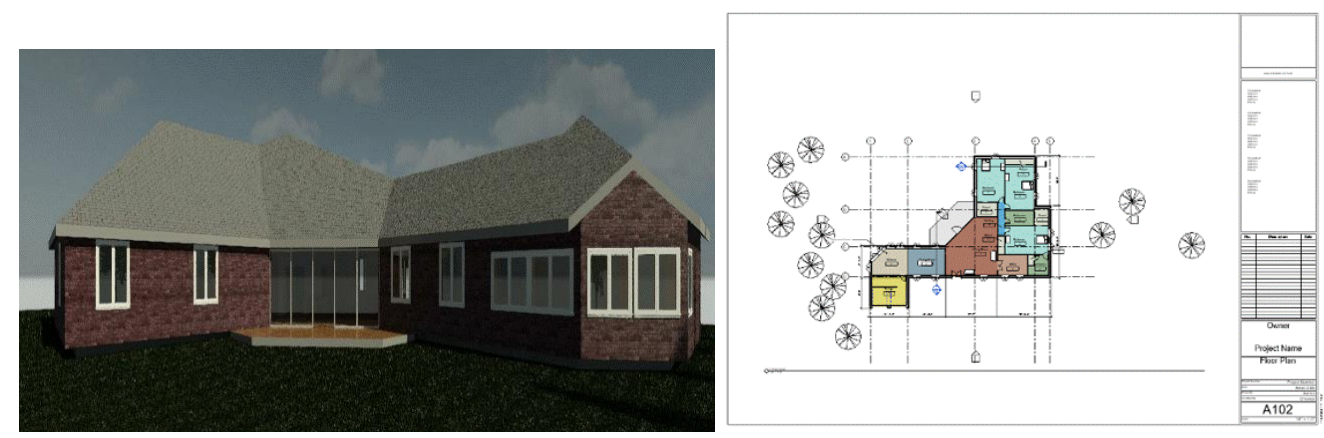

Figure 3. Student final project in construction graphics course

Toward the end of the semester, students start to create plans and schedules. The connection between the $3 \mathrm{D}$ view and the plan view derived was challenging to some students who had no previous construction experience.

At the end of the course, 15 students out of 20 registered students answered the course evaluation questions related to 3D modeling. Figures 4-6 shows the detailed questions and responses obtained. As most students enter the class without previous 3D modeling experience, it was not surprising that 14 out of 15 students agreed that the course increased their knowledge of the topic. Eighty-eight percent of the surveyed students thought that using 3D modeling improved their understanding of construction plan reading, and $80 \%$ of the students believed using 3D models in this class would enhance their performance in other construction classes.

My knowledge of the course topic has increased as a result of

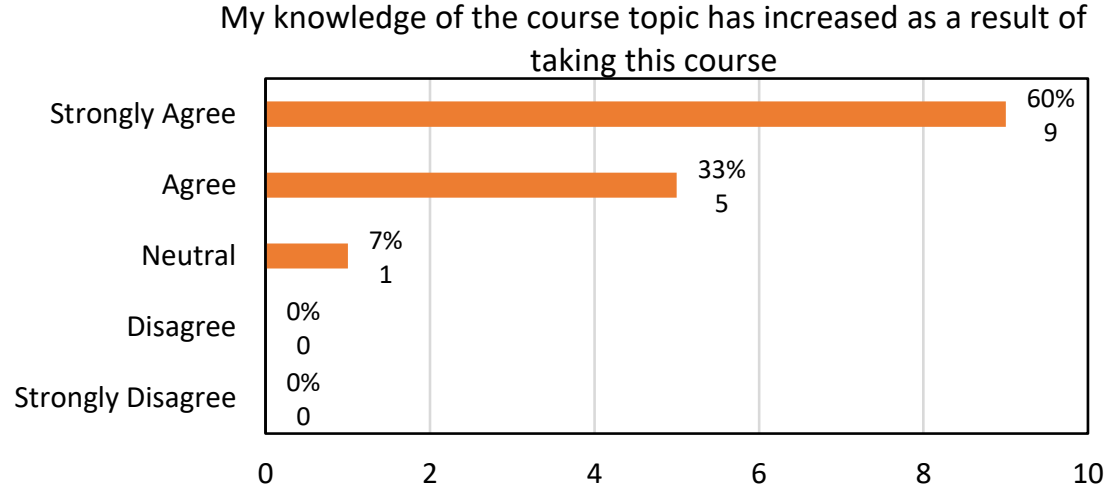


Figure 4. Construction graphics course students' responses related to their knowledge of the topic

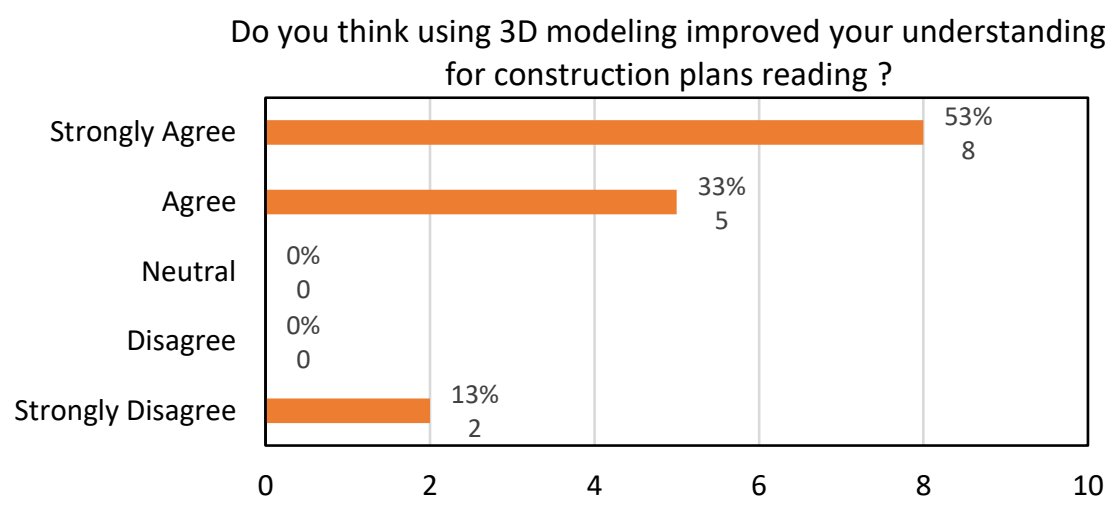

Figure 5. Construction graphics course students' responses to the question: Do you think using 3D modeling improved your understanding for construction plans reading?

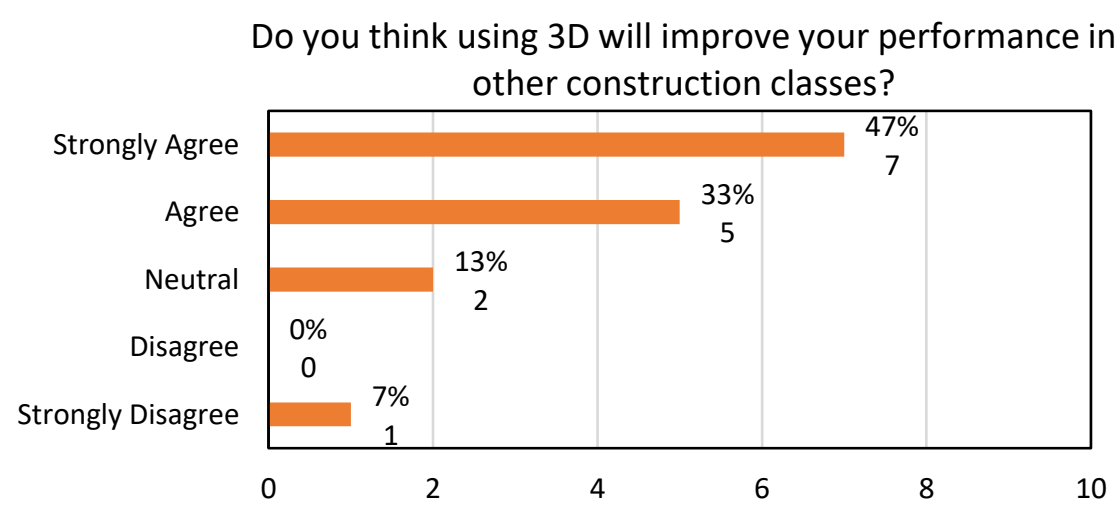

Figure 6. Construction graphics course students' responses to the question: Do you think using 3D modeling will improve your performance in other construction classes?

\section{Estimating Course}

Estimating course is a 300-level class. Students registered for the class have established a good understanding of the construction topics and already have to work through a required internship.

Although the typical practice to include 3D modeling in an estimating course uses advanced BIM techniques to quantify the plans, this method was not used in the class as the program enrollment has a high number of transfer students from community colleges. That led to variances in the students' 
readiness for this course. Therefore, 3D modeling is used to visualize the plans to help students prepare a cost estimation using 2D plans.

The class starts with a review of the material and the related assemblies, followed by the basics of estimation skills required for this material. The next class applies these skills to simple examples. Students are given a 2D plan of the example, and a 3D model is shown and discussed by the teacher. The quantity takeoff (QTO) is performed using the 2D plan and by establishing the concept on the 3D models.

This method helped students to visualize what they were performing the QTO on. It was explicitly helpful for steel framing and reinforced concrete materials. It was beneficial for students who did not start their degree work in this program. Figure 7 shows the 3D model of the reinforced concrete foundation example discussed in the class.
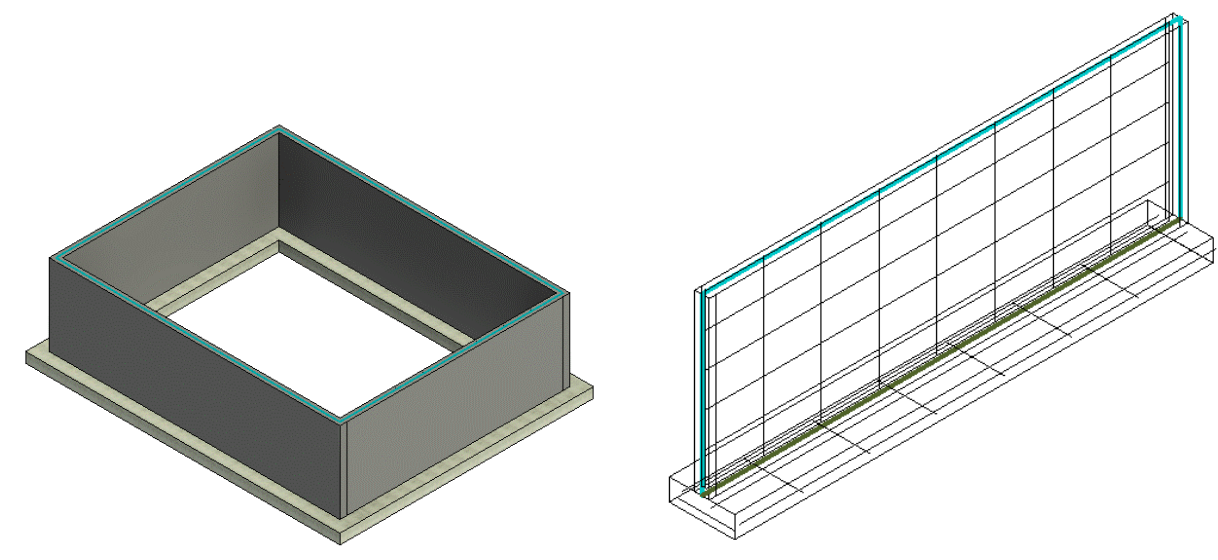

Figure 7. Reinforced concrete 3D model

At the end of the course, 19 students out of 20 registered students answered the evaluation question related to 3D modeling. Only fifty percent of the surveyed students thought that 3D modeling helped them in the estimating class (Figure 8). This is lower than the other two courses discussed in this paper. It could be related to the fact that the 3D model's usage in the class was not directly associated with the estimating skills students are learning but rather to visualize the plans, and some students in the class had already developed this skill. 


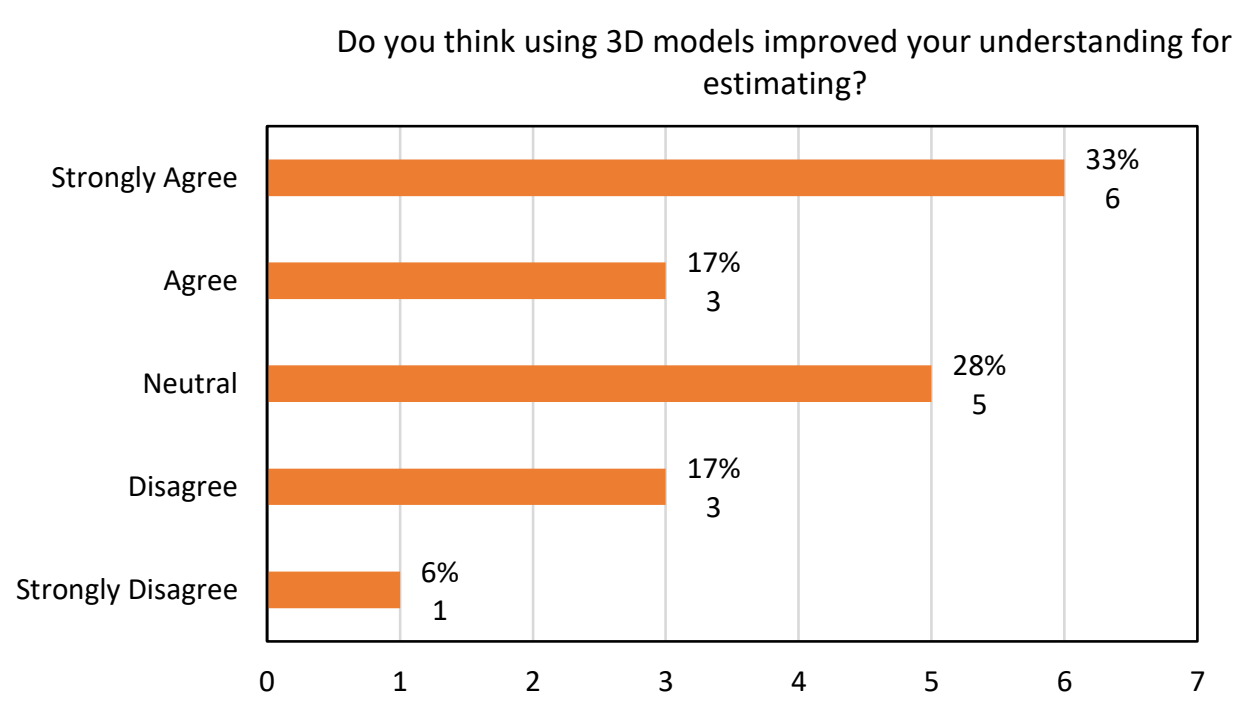

Figure 8. Estimating course students' responses

\section{Conclusions and Future Work}

The three-dimensional (3D) modeling provides the instructors with a mechanism that can enhance the teaching of architectural, engineering, and construction (AEC) students' performance more visually and engagingly.

In this research, the benefits of using 3D models in several courses in the construction management undergraduate program were investigated. Three courses were picked to implement the 3D models: Materials and Methods of Construction, Construction Graphics, and Estimating. The students' input was collected at the end of the semester and analyzed.

Seventy-one percent of the students in the Materials and Methods of Construction course believed using 3D modeling improved their understanding of construction material. In the Construction Graphics course, eighty-eight percent of the surveyed students thought that using 3D modeling improved their understanding of construction plan reading, and $80 \%$ of the students believed using 3D models in this class would enhance their performance in other construction classes. These numbers dropped in the estimating class, where only fifty percent of the surveyed students thought that 3D modeling helped them in estimating class. This could be related to the fact that using the 3D models in the class was not directly associated with the estimating skills students are learning, but rather on emphasizing the previous skills that should have been developed.

The findings indicated a clear impact of using 3D modeling in the course of Materials and Methods and Construction Graphics with less influence on the Estimating course. The findings encourage the use of 3D modeling to become generalized and used in more courses.

In the future, 3D modeling should be implemented in more courses in the construction management program, and more models should be used in each course. Collaboration between faculty members 
would be necessary to achieve this target. If possible, data should be collected over the years to be able to see the importance of 3D modeling on the students from the freshman year to graduation.

The ideal evaluation method would be to divide each class into two groups: one group with 3D modeling implemented in the course and a second group without these models. The groups' performance in the assignments related to the models can then be compared over the semester. That will be extremely hard to achieve for courses offered as one section and will also put the second group of students at a disadvantage. Also, the effect of students' previous involvement in the industry and the academic level was not tracked during this research.

\section{References}

Burgett, J. M. (2016). Leveraging Immersion Technologies in Construction Management Education : A National Electrical Code 3D Simulation Tool. ASC Annual International Conference Proceedings.

Gier, D. M. (2008). What Impact Does Using Building Information Modeling Have on Teaching Estimating to Construction Management Students? ASC Annual Intrnational Conference, 12.

Glick, S., Porter, D., \& Smith, C. (2012). Student Visualization: Using 3-D Models in Undergraduate Construction Management Education. International Journal of Construction Education and Research, 8(1), 26-46. https://doi.org/10.1080/15578771.2011.619247

Hain, A., \& Motaref, S. (2020). Implementing Interactive 3-D Models in an Entry Level Engineering Course to Enhance Students' Visualization. ASEE Conferences.

IMI. (2015). 01.030.0302: Base of Wall Detail. https://www.imiweb.org/01-030-0302-base-of-walldetail-flexible-flashing-drip-edge-term-bar-mdcd-2-tooltip/

IMI. (2019). MASONRY DETAILING SERIES. MASONRY DETAILING SERIES.

https://www.imiweb.org/masonry-detailing-series-3/

Irizarry, J., Meadati, P., Barham, W. S., \& Akhnoukh, A. (2012). Exploring Applications of Building Information Modeling for Enhancing Visualization and Information Access in Engineering and Construction Education Environments. International Journal of Construction Education and Research, 8(2), 119-145. https://doi.org/10.1080/15578771.2011.647247

Kember, D., \& McNaught, C. (2007). Enhancing University Teaching: Lessons from research into award-winning teachers. In Enhancing University Teaching: Lessons From Research Into AwardWinning Teachers. https://doi.org/10.4324/9780203962947

Kolb, D. A. (1981). Learning styles and disciplinary differences. The Modern American College. Official Google, B. (2016). 3D Warehouse. https://3dwarehouse.sketchup.com/?hl=en

Sampaio, A. Z., Ferreira, M. M., Rosário, D. P., \& Martins, O. P. (2010). 3D and VR models in Civil Engineering education: Construction, rehabilitation and maintenance. Automation in Construction, 19(7), 819-828. https://doi.org/10.1016/j.autcon.2010.05.006

Schreyer, A. C. (2014). 3D Modeling and Virtual Mockup Building as Teaching Tools in AEC Materials and Methods Curricula. ASC 50th Annual International Conference / CIB Workgroup 89, 9. 